\title{
Factors affecting the emergency room treatment of boxer's fractures
}

\author{
Rizwan Mian MD, Christopher Scilley MD FRCSC \\ London Health Sciences Centre, London, Ontario
}

R Mian, C Scilley. Factors affecting the emergency room treatment of boxer's fractures. Can J Plast Surg 1996;4(2):99-100. There is considerable controversy over the point at which boxer's fractures need to be reduced. This study characterizes the features of fractures that prompted reduction. A retrospective review of 57 consecutive patients with 57 boxer's fractures presenting to the emergency room was carried out. Forty percent of the fractures were reduced. With reduction, the average angulation on lateral radiographs improved from $40.5^{\circ}$ to $31.6^{\circ}$. The improvement of angulation, after reduction, was statistically significant $(\mathrm{P}<0.005)$. After an average of 17 days follow-up period the angulation was $35.2^{\circ}$. There was no significant loss of reduction shown between the post reduction and follow-up radiographs $(\mathrm{P}>0.1)$.

Key words: Boxer's fracture, Metacarpal

Facteurs affectant le traitement des fractures du boxeur à l'urgence

RÉSUMÉ : Une importante controverse règne au sujet du moment où les fractures du boxeur doivent être réduites. Cette étude établit les caractéristiques de fractures qui justifient leur réduction. On a procédé à une revue rétrospective des dossiers de 57 boxeurs vus à l'urgence, totalisant 57 fractures. Quarante pour cent des fractures ont été réduites. Grâce à la réduction, l'angulation moyenne aux radiographies latérales s'est améliorée, passant de 40,5 à $31,6^{\circ}$. L'amélioration de l'angulation après la réduction s'est révélée statistiquement significative $(\mathrm{P}<0,005)$. Après une moyenne de 17 jours de suivi, l'angulation était de $35,2^{\circ}$. Aucune perte significative de la réduction n'est survenue entre le moment des radiographies post-réduction et des radiographies au moment du suivi $(\mathrm{P}>0,1)$.

Fractures through the neck of the metacarpal of the small finger are commonly known as boxer's fractures. There is considerable controversy over the appropriate treatment of these fractures when there is no component of malrotation. Malrotated fractures require reduction $(1,2)$. Some authors suggest that angulated Boxer's fractures do not need to be reduced (3), others recommend reduction but vary over the degree of angulation that necessitates reduction. The recommendations vary from $20^{\circ}$ to $70^{\circ}$ of angulation, but a guideline of $40^{\circ}$ has been suggested (4-6). This may represent a difference in methods of measuring the angulation but also represents a difference of opinions (4). There is normally $15^{\circ}$ of angulation of the neck of the small finger metacarpal (3).

Because of the variety of recommendations proposed for the treatment of boxer's fractures we decided to review the emergency room treatment experience at London Health Sciences Centre in London, Ontario. 


\section{METHODS}

The radiographs and emergency room charts of patients diagnosed with a boxer's fracture between September 1, 1993 and February 28, 1994 were reviewed by one author (RM). Only fractures of the small finger metacarpal neck were included. The age, sex and side of injury of the patients was recorded. The handedness, exact mechanism of injury and occupation were inconsistently recorded and could not be evaluated. All fractures were treated closed. Patients were discharged from the emergency room in an ulnar gutter splint. The splint held the wrist in $30^{\circ}$ to $45^{\circ}$ degrees of extension, the metacarpal phalangeal joints in $70^{\circ}$ to $90^{\circ}$ degrees of flexion and the interphalangeal joints in full extension. The initial, post reduction (if applicable) and follow-up radiographs were reviewed. Lateral and oblique radiographs were assessed for degree of angulation. A line was drawn along the long axis of the metacarpal shaft and another along the axis of the neck and through the centre of the head of the metacarpal. The angle between these lines was measured (2). It was felt that there was no good method available that would eliminate potential measurement error due to alteration in radiographic technique (RG Haddad, personal communication). The unreduced and reduced fractures were compared using the t-test and of the reduced fractures, the initial, post reduction and follow-up values were also compared with a paired t-test. A P value of 0.05 was selected.

\section{RESULTS}

A total of 57 patients with 57 fractures were studied. The average age was 23 years for the entire sample (range of nine to 68 years). The average age in the reduced group was significantly greater than in the unreduced group ( 25 versus 23 years, respectively; $\mathrm{P}<0.01)$. The clinical relevance of this difference is not clear. Ninety-three per cent of the patients were male. The right hand was affected $89 \%$ of the time. Forty per cent of the fractures were reduced. Seventy-eight per cent of the reduced fractures were followed up at London Health Sciences Centre. On average the last follow-up radiograph was 17 days post injury (range five to 35 days). Thirty-two per cent of the patients with unreduced fractures presented for follow-up, with an average final radiograph at 14 days (range six to 30 days). The patients were followed up clinically for several weeks, until the fractures were deemed to be stable. The reduced fractures had a significantly greater angulation than did those that were not reduced $(\mathrm{P}<0.005)$. The former fractures had an average angulation of greater than $40^{\circ}$ in both the oblique and lateral views, while the latter averaged closer to $30^{\circ}$ (Table 1). There was a statistically significant decrease in the angulation of the reduced fractures both immediately post reduction and at follow-up $(\mathrm{P}<0.005$ and $\mathrm{P}<0.05$, respectively). There was no statistical difference between the post reduction angulation and the follow-up angulation $(\mathrm{P}>0.1$, (Table 2). This indicates that the reductions achieved in the emergency room were not lost during follow-up. Similarly, of the fractures that were not reduced, there was no statistical difference between the initial and follow-up angulations $(\mathrm{P}>0.1)$. 
ER treatment of boxer's fractures

TABLE 1: Average initial angulation of the reduced versus the not reduced groups

$\begin{array}{lcccc} & \text { Lateral (SD) } & \text { Range } & \text { Oblique (SD) } & \text { Range } \\ \text { Reduced } & 40.5(7.54) & 25-55 & 45.3(10.06) & 29-68 \\ \begin{array}{l}\text { Not } \\ \text { reduced }\end{array} & 30.1(7.61) & 18-50 & 37.8(8.26) & 22-54\end{array}$

\author{
TABLE 2: Average angulation of the reduced fractures initially, post reduction and follow- \\ up

$\begin{array}{lccc} & \text { Initial } & \text { Post reduction } & \text { Follow-up } \\ \text { Lateral } & 40.5 & 31.6 & 35.2 \\ \text { Oblique } & 45.3 & 36.2 & 38.1\end{array}$

\title{
DISCUSSION
}

There was some inconsistency in regards to the point at which a boxer's fracture should be reduced, as can be seen from the large standard deviations of the reduced fracture group (lateral 7.54, oblique 10.06). The fractures that underwent reduction were more angulated than those in the unreduced group, both in the lateral and oblique views. The decision to reduce a fracture seemed to be somewhat arbitrary, with no great distinguishing features between fractures that were reduced and those that were not. The reductions improved the angulation but rarely restored anatomic position. Notably, the reductions were not lost, according to follow-up radiographs. The reductions seemed to be effective when assessed statistically but the clinical significance has yet to be determined. Studies of longer follow-up periods with assessments of hand function and patient satisfaction would help with clinical guidelines. The unreduced fractures encompassed a large proportion of this study group with a wide range of angulations. Few long term problems were identified with either group, as there were no requests for reassessment from patients dissatisfied with their long term outcome. From this initial assessment of the treatment of boxer's fractures at London Health Sciences Centre, it seems that guidelines might be helpful to facilitate decision making in the emergency room and encourage consistency in treatment. As a result of this study several recommendations can be made: encourage follow-up for all patients to assess outcomes better, continue to use $40^{\circ}$ of angulation as a guide for reduction, and conduct further studies of this problem in order to determine better the most efficacious method of treatment.

\section{REFERENCES}

1. Bowman SH, Simon RR. Metacarpal and phalangeal fractures. Emerg Med Clin North Am 1993;11:671-702.

2. Theeuwen GA, Lemmens JA, Van Niekerk JL. Conservative treatment of boxer's fracture: a retrospective analysis. Injury 1991;22:390-4. 
3. Ford DJ, Ali MS, Steel WM. Fractures of the fifth metacarpal neck: Is reduction or mobilization necessary? J Hand Surg 1989;14:165-7.

4. Konradsen L, Nielsen PT, Albrecht-Beste E. Functional treatment of metacarpal fractures. Acta Ortho Scan 1990;61:531-4.

5. Mian RA, Mian IA. Hand fractures. Med J UWO 1994;63:94-6.

6. Ashkenaze DM, Ruby LK. Metacarpal fractures and dislocations. Orthop Clin North Am 1992;23:19-33. 